\title{
The metabolic syndrome of fructose-fed rats: Effects of long-chain polyunsaturated $\omega 3$ and $\omega 6$ fatty acids. IV. D-glucose metabolism by isolated pancreatic islets
}

\author{
ZOHEIR MELLOUK $^{1}$, YING ZHANG ${ }^{2}$, NURDAN BULUR ${ }^{2}$, KARIM LOUCHAMI $^{2}$, \\ ABDULLAH SENER $^{2}$, DALILA AIT YAHIA ${ }^{1}$ and WILLY J. MALAISSE ${ }^{2}$ \\ ${ }^{1}$ Department of Biology, Es-Sénia University, Oran, Algeria; ${ }^{2}$ Laboratory of Experimental \\ Hormonology, Université Libre de Bruxelles, Brussels, Belgium
}

Received July 6, 2011; Accepted September 2, 2011

DOI: $10.3892 / \mathrm{ijmm} .2011 .824$

\begin{abstract}
The major aim of the present study was to search for changes of D-glucose metabolism in isolated pancreatic islets possibly involved in the alteration of their secretory response to the hexose, as observed when comparing rats exposed for 8 weeks to diets containing either starch and sunflower oil or fructose and sunflower oil, as well as rats exposed to diets containing fructose, sunflower oil and either salmon oil or safflower oil. The substitution of starch by fructose in the diet affected unfavourably D-glucose phosphorylation by the isolated islets. In the fructose-fed rats, there was a close parallelism between D-[5- $\left.{ }^{3} \mathrm{H}\right]$ glucose utilization and the dietary $\omega 3 / \omega 6$ fatty acid ratio. There was little to distinguish, however, between the four groups of rats in terms of $\mathrm{D}-\left[\mathrm{U}-{ }^{14} \mathrm{C}\right]$ glucose oxidation. The paired ratio between $\mathrm{D}-\left[\mathrm{U}-{ }^{14} \mathrm{C}\right]$ glucose oxidation and D-[5- $\left.{ }^{3} \mathrm{H}\right]$ glucose utilization, which always increased as the concentration of the hexose was raised from 2.8 to 8.3 and $16.7 \mathrm{mM}$, was tightly related, in the fructose-fed rats, to the HOMA index for insulin resistance.
\end{abstract}

\section{Introduction}

In the present series of reports dealing with the metabolic and hormonal effects of dietary long-chain polyunsaturated $\omega 3$ and $\omega 6$ fatty acids in rats exposed to a fructose-rich diet, emphasis was so far placed on i) the changes in glucose tolerance, insulinogenic index and insulin resistance, as assessed during an intraperitoneal glucose tolerance test, ii) the time course of changes in such variables as body weight, food intake, plasma

Correspondence to: Professor Willy J. Malaisse, Laboratory of Experimental Hormonology, Université Libre de Bruxelles, 808 Route de Lennik, B-1070 Brussels, Belgium

E-mail: malaisse@ulb.ac.be

Key words: metabolic syndrome, fructose-fed rats, long-chain polyunsaturated $\omega 3$ and $\omega 6$ fatty acids, pancreatic islets, D-glucose metabolism
D-glucose and insulin concentrations over 8 weeks exposure to the four diets considered in this study, and iii) the insulin secretory behaviour and insulin content of pancreatic islets isolated from the rats at sacrifice (1-3). The present report concerns the metabolic fate of D-glucose in isolated pancreatic islets incubated in vitro at increasing concentrations of D-glucose. The major aim of such a study was to search for changes in D-glucose catabolism possibly involved in the alteration of the secretory response of the islets to this hexose.

\section{Materials and methods}

Pancreatic islets were collected after overnight starvation by the collagenase method, as described in the preceding article in this series. Groups of 20 islets were incubated for $90 \mathrm{~min}$ at $36^{\circ} \mathrm{C}$ in $50 \mu \mathrm{l}$ of a salt-balanced medium (4) containing $1.0 \mathrm{mg} / \mathrm{ml}$ bovine serum albumin and equilibrated against a mixture of $\mathrm{O}_{2} / \mathrm{CO}_{2}(95 / 5, \mathrm{v} / \mathrm{v})$. The generation of tritiated $\mathrm{H}_{2} \mathrm{O}$ from D-[5- $\left.{ }^{3} \mathrm{H}\right]$ glucose (glucose utilization) and ${ }^{14} \mathrm{CO}_{2}$ from D-[U- $\left.{ }^{14} \mathrm{C}\right]$ glucose (glucose oxidation) were measured by methods described elsewhere (5).

All results are presented as mean values ( \pm SEM) together with the number of individual observations (n). The statistical significance of differences between mean values was assessed by use of Student's t-test.

\section{Results}

$D-\left[-U-{ }^{14} C\right] g l u c o s e$ oxidation. As indicated in Table I, when expressed as D-glucose equivalent per islet over $90 \mathrm{~min}$ incubation, the oxidation of D-[-U- $\left.{ }^{14} \mathrm{C}\right]$ glucose progressively increased from $2.7 \pm 0.3(\mathrm{n}=49)$ at $2.8 \mathrm{mM}$ D-glucose to $8.5 \pm 0.8$ $(n=49)$ and $15.7 \pm 2.1(n=47)$ at 8.3 and $16.7 \mathrm{mM}$ D-glucose, respectively. As a rule the mean values recorded at each concentration of the hexose failed to differ significantly in the four different groups of rats. A trend towards a lower oxidative rate was observed in the (Fsal) rats. Yet, when all results were expressed relative to the mean corresponding values found at the same concentration of D-glucose in the (Ssun) rats, a significant difference $(\mathrm{p}<0.05)$ between the values recorded in the (Fsal) rats $(67.6 \pm 6.4 \% ; n=35)$ and those recorded in the 
Table I. D-[-U- $\left.{ }^{14} \mathrm{C}\right]$ glucose oxidation (pmol/islet per $90 \mathrm{~min}$ ).

\begin{tabular}{lccc}
\hline Rats & $2.8 \mathrm{mM}$ D-glucose & $8.3 \mathrm{mM}$ D-glucose & $16.7 \mathrm{mM}$-glucose \\
\hline Ssun & $3.11 \pm 1.20(12)$ & $11.09 \pm 2.40(11)$ & $14.82 \pm 3.29(10)$ \\
Fsun & $3.64 \pm 0.47(9)$ & $9.02 \pm 1.60(9)$ & $14.63 \pm 1.97(9)$ \\
Fsal & $2.37 \pm 0.31(11)$ & $5.02 \pm 0.65(12)$ & $12.18 \pm 2.01(12)$ \\
Fsaf & $2.19 \pm 0.39(17)$ & $9.07 \pm 1.41(17)$ & $19.41 \pm 5.64(16)$ \\
\hline
\end{tabular}

Table II. D-[5-3 ${ }^{3}$ ]glucose utilization (pmol/islet per $90 \mathrm{~min}$ ).

\begin{tabular}{lccc}
\hline Rats & $2.8 \mathrm{mM}$ D-glucose & $8.3 \mathrm{mM}$ D-glucose & $16.7 \mathrm{mM}$ D-glucose \\
\hline Ssun & $110.5 \pm 32.4(11)$ & $185.0 \pm 43.4(11)$ & $225.4 \pm 48.8(12)$ \\
Fsun & $64.0 \pm 7.4(9)$ & $118.8 \pm 8.0(9)$ & $172.7 \pm 15.1(9)$ \\
Fsal & $98.8 \pm 10.7(12)$ & $155.6 \pm 14.7(11)$ & $267.6 \pm 23.9(12$ \\
Fsaf & $46.9 \pm 5.5(14)$ & $88.3 \pm 7.5(17)$ & $141.0 \pm 16.9(16)$ \\
\hline
\end{tabular}

Table III. ${ }^{14} \mathrm{CO}_{2} /{ }^{3} \mathrm{HOH}$ ratio (\%).

\begin{tabular}{lccc}
\hline Rats & $2.8 \mathrm{mM}$ D-glucose & $8.3 \mathrm{mM}$ D-glucose & 16.7 mM D-glucose \\
\hline Ssun & $1.82 \pm 0.79(11)$ & $7.82 \pm 1.06(11)$ & $9.14 \pm 1.86(10)$ \\
Fsun & $6.58 \pm 1.28(9)$ & $7.98 \pm 1.49(9)$ & $8.73 \pm 0.97(9)$ \\
Fsal & $2.69 \pm 0.43(11)$ & $3.36 \pm 0.46(11)$ & $4.95 \pm 0.93(12)$ \\
Fsaf & $4.87 \pm 0.85(13)$ & $9.86 \pm 0.94(17)$ & $12.41 \pm 2.86(15)$ \\
\hline
\end{tabular}

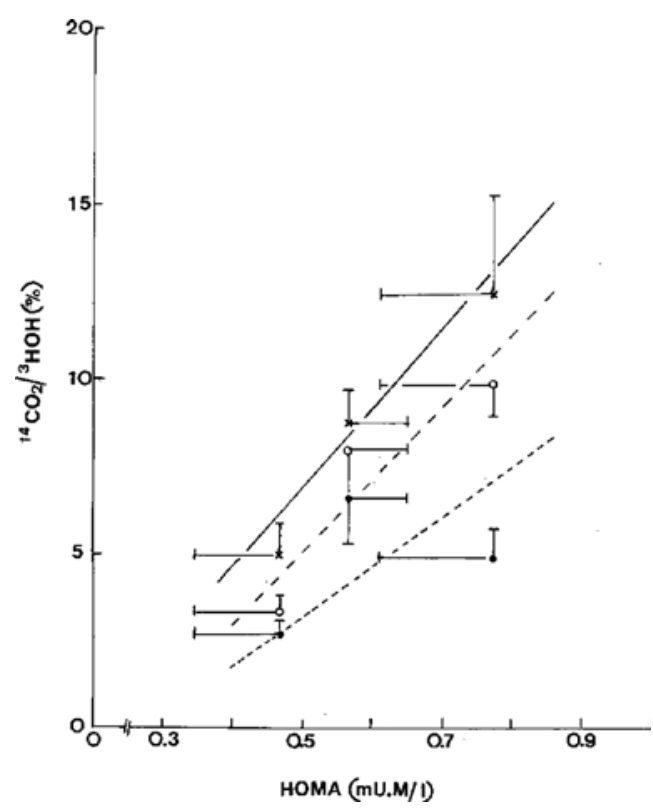

Figure 1. Comparison between the mean values $( \pm \mathrm{SEM})$ for the ${ }^{14} \mathrm{CO}_{2}{ }^{\beta} \mathrm{HOH}$ ratio ( $\mathrm{n}=9-15)$ in islets exposed to $2.8 \mathrm{mM}$ D-glucose (closed circles), $8.3 \mathrm{mM}$ D-glucose (open circles) or $16.7 \mathrm{mM} \mathrm{D}$-glucose (crosses) and isolated (from left to right) from (Fsal) rats, (Fsun) rats and (Fsaf) rats, on one hand, and the mean values $( \pm$ SEM) for the HOMA index found in the same three groups of rats at time zero of an intraperitoneal glucose tolerance test. The oblique solid and dashed lines correspond to the regression lines derived from the mean data recorded at $16.7 \mathrm{mM}$ and $8.3 \mathrm{mM}$ D-glucose, respectively. Likewise, the oblique dotted line corresponds to the regression lines based on the mean data recorded at $2.8 \mathrm{mM}$ D-glucose in either (Fsal) rats or (Fsun) and (Fsaf) rats. other 3 groups of rats was only reached by comparison with the overall mean value $(96.9 \pm 8.2 \% ; n=110)$ found in the (Ssun) rats $(100.0 \pm 16.7 \% ; n=33)$, the (Fsun) rats $(99.0 \pm 8.4 \% ; n=27)$ and the (Fsaf) rats $(93.8 \pm 13.8 \% ; n=50)$.

D- $\left[5-{ }^{3} \mathrm{H}\right]$ glucose utilization. Relative to the average of the mean values recorded at each concentration of D-glucose $(2.8,8.3$ and $16.7 \mathrm{mM}$ ) within each experiment in islets from the same group of rats, no significant difference was observed between the measurements of $\mathrm{D}-\left[5-{ }^{3} \mathrm{H}\right]$ glucose utilization made in each type of rats (Ssun, Fsun, Fsal, Fsaf). At 2.8, 8.3 and $16.7 \mathrm{mM}$ D-glucose, respectively, the overall mean values amounted to $54.7 \pm 3.1 \%(\mathrm{n}=46), 96.0 \pm 4.0 \%(\mathrm{n}=48)$ and $148.1 \pm 6.5 \%(\mathrm{n}=49)$.

The absolute values for $\mathrm{D}-\left[5-{ }^{3} \mathrm{H}\right]$ glucose utilization differed significantly, however, from one another in selected instances. First, the values recorded in the (Fsun) rats averaged no more than $66.1 \pm 3.3 \%(n=27 ; p<0.04)$ of the mean corresponding values found at the same D-glucose concentration in islets from (Ssun) rats $(100.0 \pm 13.9 \%$; $n=34)$. Second, expressed in the same manner, the mean values recorded in the (Fsal) rats $(97.8 \pm 6.0 \% ; \mathrm{n}=35)$ were higher $(\mathrm{p}<0.001)$ and those recorded in the (Fsaf) rats $(50.4 \pm 3.5 \% ; n=47)$ lower $(\mathrm{p}<0.005)$ than those found in the (Fsun) rats (Table II).

${ }^{14} \mathrm{CO}_{2}{ }^{3} \mathrm{HOH}$ ratio. In all four groups of rats, the paired ratio between D-[-U $\left.-{ }^{14} \mathrm{C}\right]$ glucose oxidation and $\mathrm{D}-\left[5-{ }^{3} \mathrm{H}\right]$ glucose utilization increased as a function of the concentration of the hexose. Relative to the averaged derived from the man values 
recorded at each concentration of D-glucose in each experiment and in each group of rats, such a ratio indeed increased $(\mathrm{p}<0.001)$ from $58.8 \pm 6.0 \%(\mathrm{n}=44)$ at $2.8 \mathrm{mM}$ D-glucose to $109.6 \pm 5.8 \%$ $(\mathrm{n}=48)$ at $8.3 \mathrm{mM}$ D-glucose and further increased $(\mathrm{p}<0.07)$ to $132.2 \pm 10.4 \%(\mathrm{n}=46)$ at $16.7 \mathrm{mM}$ D-glucose. In this respect, no significant difference ( $p>0.14$ or more) was observed between the different groups of rats when expressing the values reached at each concentration of the hexose relative to those recorded in the (Ssun) rats and comparing the overall mean values derived from such comparisons in each of the four groups of rats.

The absolute values for the ${ }^{14} \mathrm{CO}_{2} /{ }^{3} \mathrm{HOH}$ ratio averaged at $2.8,8.3$ and $16.7 \mathrm{mM}$ D-glucose, respectively $3.0 \pm 0.5 \%(\mathrm{n}=44)$, $7.6 \pm 0.6 \%(\mathrm{n}=48)$ and $9.0 \pm 1.1 \%(\mathrm{n}=46)$. When expressed relative to those recorded at the same concentration of D-glucose in the (Ssun) rats $(100.0 \pm 16.4 \% ; n=32)$, such absolute values failed to differ significantly ( $>0.33$ ) in these (Ssun) rats and in the (Fsal) rats $(80.7 \pm 11.7 \% ; \mathrm{n}=34)$. Likewise, at 8.3 and $16.7 \mathrm{mM}$ D-glucose, the values recorded in the (Fsun) rats $(98.8 \pm 10.6 \%$; $\mathrm{n}=18 ; \mathrm{p}>0.93)$ or in the (Fsaf) rats $(130.6 \pm 15.7 \% ; \mathrm{n}=32 ; \mathrm{p}>0.17)$ failed to differ significantly from those found in the (Ssun) rats $(100.0 \pm 11.7 \% ; \mathrm{n}=21)$. At $5.6 \mathrm{mM} \mathrm{D}$-glucose, however, the mean values found in each of the three groups of fructose-fed rats exceeded those recorded in the (Ssun) rats $(100.0 \pm 43.6 \%$; $\mathrm{n}=11)$, averaging $147.5 \pm 23.8 \%(\mathrm{n}=11 ; \mathrm{p}>0.35)$ in the (Fsal) rats, $267.7 \pm 46.9 \%(\mathrm{n}=13 ; \mathrm{p}<0.02)$ in the (Fsaf) rats and $361.1 \pm 70.2 \%$ $(\mathrm{n}=9 ; \mathrm{p}<0.005)$ in the (Fsun) rats (Table III).

\section{Discussion}

The present results concerning the utilization of $\mathrm{D}-\left[5-{ }^{3} \mathrm{H}\right]$ glucose suggest that, at least in rats exposed to a sunfloweroil diet, the substitution of starch by D-fructose affected unfavourably the total rate of hexose phosphorylation by isolated islets. Such an utilization indeed represented in the (Fsun) rats only $66.1 \pm 3.3 \%$ of the mean corresponding values found at the same concentration of D-glucose in the (Ssun) rats, i.e. $100.0 \pm 13.9 \%$. In this respect, the present results should be compared with the direct effect of D-fructose upon D-glucose phosphorylation by glucokinase (6).

In the fructose-fed rats, however, there was a close analogy between the $\mathrm{D}-\left[5-{ }^{3} \mathrm{H}\right]$ glucose utilization and the dietary $\omega 3 / \omega 6$ ratio. Thus, the generation of ${ }^{3} \mathrm{HOH}$ averaged in the (Fsal) rats, always expressed relative to the mean corresponding values found at the same hexose concentration in the (Ssun) rats, $97.8 \pm 6.0 \%$, as distinct from $66.1 \pm 3.3 \%$ in the (Fsun) rats and $50.4 \pm 3.5 \%$ in the (Fsaf) rats. These findings are in good agreement with the observation that in islet homogenates from second-generation $\omega 3$-depleted rats, the phosphorylation of D-glucose by glucokinase is impaired relative to that found in control animals (7). The latter situation was previously proposed to be attributable to the accumulation of long-chain fatty-acyl CoA in the islets of $\omega 3$-depleted rats (7).

Despite such differences in D-[5- $\left.{ }^{3} \mathrm{H}\right]$ glucose utilization, there was little to distinguish, in terms of D-[U-14 $\left.{ }^{14}\right]$ glucose oxidation, between the four groups of rats examined in the present experiments. At the most, the low values found in the (Fsal) rats $(67.6 \pm 6.4 \%$ of the corresponding reference values found at the same D-glucose concentration in the (Ssun) rats) contrasted with those recorded in either (Fsun) rats $(99.0 \pm 8.4 \%)$ or (Fsaf) rats $(93.8 \pm 13.8 \%)$.
At increasing concentrations of D-glucose, a preferential stimulation of D-[U- $\left.{ }^{14} \mathrm{C}\right]$ glucose oxidation, relative to $\mathrm{D}-\left[5-{ }^{3} \mathrm{H}\right]$ glucose utilization, was observed in all four groups of rats, with a comparable concentration-response relationship in all cases. The most obvious difference between distinct groups of rats related to the ${ }^{14} \mathrm{CO}_{2} /{ }^{3} \mathrm{HOH}$ ratio at a low concentration of D-glucose $(2.8 \mathrm{mM})$. The results found, in this respect, in the fructose-fed rats, were tightly related to the severity of insulin resistance, as judged from the HOMA index $(1,2)$. Thus, at $2.8 \mathrm{mM}$ D-glucose, the ${ }^{14} \mathrm{CO}_{2}{ }^{3} \mathrm{HOH}$ ratio averaged $2.69 \pm 0.43$ $(\mathrm{n}=11)$ in the (Fsal) rats, as distinct $(\mathrm{p}<0.02)$ from $5.57 \pm 0.73$ $(n=22)$ in the (Fsun) and (Fsaf) rats. This is illustrated in Fig. 1, which further extends the relationship between these two sets of variables to the results for the ${ }^{14} \mathrm{CO}_{2}{ }^{\beta} \mathrm{HOH}$ ratio found at higher concentrations of D-glucose $(8.3$ and $16.7 \mathrm{mM})$. Indeed, at these higher concentrations of D-glucose, the correlation coefficient between the mean values for the ${ }^{14} \mathrm{CO}_{2} /{ }^{3} \mathrm{HOH}$ ratio and HOMA index amounted to $0.964 \pm 0.003(\mathrm{n}=2)$.

In conclusion, the present metabolic data provide selected information on changes in the catabolism of D-glucose in rat pancreatic islets linked to dietary manipulations in the supply of distinct carbohydrates and distinct long-chain polyunsaturated fatty acids, as well as on the possible relevance of these changes to the insulin secretory behaviour of pancreatic islets isolated from the same animals. Further investigations should not be ignored, however, such as a comparison between the fate of exogenous nutrients other than D-glucose or the metabolism of endogenous nutrients in the islets of the four groups of rats considered in this study.

\section{Acknowledgments}

We are grateful to C. Demesmaeker for secretarial help.

\section{References}

1. Mellouk Z, Hachimi Idrissi T, Louchami K, Hupkens E, Malaisse WJ, Ait Yahia D and Sener A: The metabolic syndrome of fructose-fed rats: effects of long-chain polyunsaturated $\omega 3$ and $\omega 6$ fatty acids. I. Intraperitoneal glucose tolerance test. Int J Mol Med 28: 1087-1092, 2011.

2. Mellouk Z, Hachimi Idrissi T, Louchami K, Hupkens E, Sener A, Ait Yahia D and Malaisse WJ: The metabolic syndrome of fructose-fed rats: effects of long-chain polyunsaturated $\omega 3$ and $\omega 6$ fatty acids. II. Time course of changes in food intake, body weight, plasma glucose and insulin concentrations and insulin resistance. Int J Mol Med 29: 113-118, 2012.

3. Mellouk K, Zhang Y, Bulur N, Louchami K, Malaisse WJ, Ait Yahia D and Sener A: The metabolic syndrome of fructosefed rats: effects of long-chain polyunsaturated $\omega 3$ and $\omega 6$ fatty acids. III. Secretory behaviour of isolated pancreatic islets. Int J Mol Med 29: 285-290, 2012.

4. Malaisse WJ, Maggetto C, Leclercq-Meyer V and Sener A: Interference of glycogenolysis with glycolysis in pancreatic islets from glucose-infused rats. J Clin Invest 91: 432-436, 1993.

5. Malaisse WJ and Sener A: Hexose metabolism in pancreatic islets. Feedback control of D-glucose oxidation by functional events. Biochim Biophys Acta 971: 246-254, 1988.

6. Scruel O, Sener A and Malaisse WJ: Glucose-induced positive cooperativity of fructose phosphorylation by human B-cell glucokinase. Mol Cell Biochem 175: 263-269, 1997.

7. Zhang Y, Bulur N, Peltier S, Carpentier YA, Malaisse WJ and Sener A: Long-chain fatty acyl-coenzyme A-induced inhibition of glucokinase in islets from rats depleted in long-chain polyunsaturated $\omega 3$ fatty acids. Cell Biochem Funct 26: 233-237, 2008. 